International Journal of Child, Youth and Family Studies (2016) 7(3/4): 423-455

DOI: http://dx.doi.org/10.18357/ijcyfs73-4201616129

\title{
UNPACKING YOUNG PEOPLE'S NARRATIVES ABOUT THEIR ASPIRATIONS: A BOURDIEUSIAN PERSPECTIVE
}

\author{
Cara K.Y. Ng, Rebecca J. Haines-Saah, Carla T. Hilario, \\ Emily K. Jenkins, and Joy L. Johnson
}

\begin{abstract}
Drawing from Bourdieu's theories on habitus, capital, and field, this article explores the complex relationship between social context and youth's aspirations and perceptions of the future. Based on findings from interviews we conducted with young people in two distinct communities in British Columbia, Canada, we undertook a comparative analysis of the ways in which class and place influence young people's "imagined futures". Our findings suggest that family plays an instrumental role in shaping youth's aspirations in both locations. Perceptions regarding opportunity and mobility varied greatly between the communities, and appeared to be influenced by racialized and gendered inequalities. A few youth had aspirations that resided outside of the narrative parameters mapped out by their peers. We explore the implications of these perspectives for community-level strategies aiming to improve young people's future trajectories, which could have positive impacts on their current and future health and wellbeing. While Bourdieu's theories do not explicitly consider adolescent-specific capital, we found them to be helpful in making sense of youth's narratives about their futures.
\end{abstract}

Keywords: Bourdieu, habitus, capital, field, aspirations, youth

Cara K. Y. Ng (the corresponding author) is the Project Director for the RADAR Project at Simon Fraser University, 515 West Hastings Street, Vancouver, BC V6B 5K3. Email: cna14@sfu.ca

Rebecca J. Haines-Saah is an Assistant Professor in the Department of Community Health Sciences at the Cumming School of Medicine, University of Calgary, TRW Building, Room 3E17, 3280 Hospital Drive NW, Calgary, AB T2N 4Z6. Email: rebecca.saah@ucalgary.ca

Carla T. Hilario is a PhD candidate in the School of Nursing at the University of British Columbia, T201-2211 Wesbrook Mall, Vancouver, BC V6T 2B5. Email:

carla.hilario@nursing.ubc.ca

Emily K. Jenkins is an Assistant Professor in the School of Nursing at the University of British Columbia, T201-2211 Wesbrook Mall, Vancouver, BC V6T 2B5. Email: emily.jenkins@ubc.ca

Joy L. Johnson is a Professor in the Faculty of Health Sciences, Simon Fraser University, 8888 University Drive, Burnaby, BC V5A 1S6. Email: joy_johnson@sfu.ca 
International Journal of Child, Youth and Family Studies (2016) 7(3/4): 423-455 DOI: http://dx.doi.org/10.18357/ijcyfs73-4201616129

Young people's aspirations for educational and career goals have been shown to be influenced by structural inequalities (Allen \& Hollingworth, 2013; Archer \& Yamashita, 2003). It is well documented that class structures associated with poverty and social disadvantage can constrain aspirations and place youth at risk for poor health and social outcomes, and can diminish educational and occupational successes relative to more advantaged peers (Ceballo, 2004; Maurizi, Ceballo, Epstein-Ngo, \& Cortina, 2013; Stewart, Stewart, \& Simons, 2007; Walpole, 2003; Wilson, 2010; Yoshikawa, Aber, \& Beardslee, 2012). While such structural limitations are not linked to class or income status alone (Gonzales, 2011; Mello \& Swanson, 2007; Noguera, 2003), researchers have drawn on a variety of approaches to theorize the influence of context — structural, social, cultural, or a combination thereof — on youth's life trajectories.

Following Bourdieu and Passeron's (1977) work examining the education system in France, analyses of cultural capital have figured prominently within social education research (Dumais, 2002; Grenfell \& James, 1998). Bourdieu's theorization of cultural capital has been a staple for understanding the cultural influences on the "achievement gap" present in educational outcomes (Lareau \& Weininger, 2003). Educational theorists have long used Bourdieu’s theory of cultural and social capital to explain how families with class privilege confer advantages beyond economic benefits upon their children, facilitating success in school. Additionally, this theory has been used to illuminate how both the evaluation standards and social values of institutional fields of education may disadvantage students from working-class backgrounds (Lamont, Schmalzbauer, Waller, \& Weber, 1996; Lareau, 1989).

In terms of work and employment, Charlesworth's A Phenomenology of Working-Class Experience (2000) is one of the most influential ethnographic works to use Bourdieu's conceptual framework to call attention to the complex subjectivities and experiences of workingclass families, going beyond a simple "culture of poverty” thesis (Lewis, 1963). With an emphasis on the cultural reproduction of the "class habitus" from the inside out, Bourdieu can be seen as providing a "third way” (Grenfell \& James, 1998) for theorists seeking a middle ground between an overly structurally determined notion of life chances (i.e., Marxism), and the destabilizing, free-for-all of post-structuralist theorizing in which life choices, and the opportunities for remaking the self, appear to be unfettered by social and contextual conditions. In navigating the theoretical tensions among the influences of structure, culture, and agency on youths' aspirations and outcomes, Bourdieu's framework is valuable for exploring how structural or social contexts is often taken for granted and reproduced "from the personal inside out" (Jenkins, 1992, p. 12) rather than perceived by young people as an external influence on their lives.

In light of the complex relationship between social context and youth's aspirations and perceptions of their futures, our analysis drew from Bourdieu's "structuralist constructivism” (Bourdieu \& Wacquant, 1992, p. 11) as a theoretical lens through which to enhance our understandings of youth outcomes beyond the "top down" and deterministic approaches that 
International Journal of Child, Youth and Family Studies (2016) 7(3/4): 423-455

DOI: http://dx.doi.org/10.18357/ijcyfs73-4201616129

have informed theoretical models and research approaches in youth research in the sociological and psychological sciences.

Based on our study findings, drawn from data collected in two distinct geographical regions in British Columbia, Canada, we undertook a comparative analysis that utilized Bourdieu's theoretical framework to add to our understanding of youth's narratives about their “imagined futures” (Ball, Macrae, \& Maguire, 1999). We explore the implications of this analysis for community-level strategies aimed at improving young people's trajectories of current and future health and wellbeing.

\section{Youth Aspirations: The Literature}

Youth educational and career aspirations have been widely studied. Early empirical scholarship on how young people formulate aspirations focused on the experiences of white male youth in Wisconsin in the late 1950s, exploring the ways "social class" impacted occupational aspiration (Kao \& Tienda, 1998, p. 350; Empey, 1956). In contemporary scholarship, references to "socioeconomic status" are heavily cited in the literature as a significant factor that affects entry or non-entry into postsecondary education (Bowden \& Doughney, 2010; Foley, 2007; James, 2000). "Students from high socioeconomic status backgrounds are ... more likely to enrol in a university degree", creating the result of "social reproduction; a process whereby characteristics of a given social structure are ... perpetuated over time” (Bowden \& Doughney, 2012, p. 1). One's cultural resources, such as parents' levels of education and their occupational status, rather than simply one's material wealth, have also been seen as significant in determining one’s socioeconomic status (De Graaf, De Graaf, \& Kraaykamp, 2000).

Studies in the past few decades have also explored the educational and career aspirations of other demographics such as young women, and minority, immigrant, and children-ofimmigrant youth (Abada, Hou, \& Ram, 2008; Behnke, Piercy, \& Diversi, 2004; Kao \& Tienda, 1998; Alexander \& Eckland, 1974). Early studies on the role of "sex differences" on educational and vocational aspirations pointed to gendered disparities in both domains (Alexander \& Eckland, 1974; Sewell, 1971). As Osipow and Fitzgerald (1996) contend, "gender is clearly one of the most powerful influences on vocational behavior" (p. 63). Since the 1970s, young women's career interests have broadened significantly. Recent studies suggest that females demonstrate a greater interest in a wider range of careers, and more gender-role flexibility in their career ambitions, than males (Domenico \& Jones, 2006; Francis, 2002). However, Watson, Quatman, and Edler (2002) also discovered that young women tend to feel more conflicted than their male counterparts between career ambitions on the one hand, and the responsibilities associated with marriage and family on the other.

Differences in educational outcomes within and between immigrant and visible minority groups have typically focused on "cultural versus structural" explanations (Kao \& Thompson, 2003). While cultural factors have been employed to explain "superior outcomes" seen in certain 
International Journal of Child, Youth and Family Studies (2016) 7(3/4): 423-455 DOI: http://dx.doi.org/10.18357/ijcyfs73-4201616129

groups of young people, structural factors are viewed as "paramount" in explaining "inferior outcomes" achieved by others (Theissen, 2009, p. 6). In the Canadian context, Krahn and Taylor's (2005) study on the educational aspirations of youth across the country concluded that “young Canadians, and particularly [visible minority immigrant] youth, value education” (p. 430). The factors driving higher aspirations among the latter group appeared to be parental education and aspiration for their children combined with higher grades and level of school engagement. However, the authors also argue that for some racialized youth, the increasing exposure to "systemic racism and blocked opportunities in their pursuit of career goals" can produce feelings of disillusionment (p. 430).

Victor Thiessen (2009) studied the educational outcomes of visible minority and immigrant youth across nine "population groups" in Canada in an effort to help determine why some visible minority and immigrant youth fare better than others in this realm. He found that the combination of structural location and cultural attributes is connected to educational pathways for youth from different ethnic or immigrant populations, but operates in "distinctive ways” depending on the group (p. 29). Prior research in the Canadian context has demonstrated significant inequalities between Indigenous students and non-Indigenous students in educational attainment, with Indigenous youth being much less likely to participate in postsecondary education than their non-Indigenous counterparts (Aman \& Ungerleider, 2008). Regarding academic performance and educational attainment, studies also demonstrate that Asian Canadians are more likely to attend post-secondary schools than other ethnic groups, and African Canadians perform below European Canadians (Crysdale, King, \& Mandell, 1999; Finnie, Lascelles, \& Sweetman, 2005). According to Thiessen (2009), the differences in postsecondary education can be explained by a host of structural and cultural advantages and disadvantages that modulate young people’s experience of the educational system.

In the United Kingdom, scholars have critically engaged with government policy and its focus on young people's social mobility and aspirations (Milestone, 2016; Noonan, 2015; Allen \& Hollingworth, 2013). Within this body of scholarship, there are only a few comparative qualitative studies exploring the implications of place on young people's ambitions for the future (Evans, 2016; Donnelly \& Evans, 2015; Allen \& Hollingworth, 2013).

Absent from the existing literature is a qualitative analysis of young people's aspiration narratives within the Canadian context that compares youth from different communities. While there have been studies that have examined the educational, professional, and mobility aspirations of rural and urban young people living in Atlantic Canada and Ontario using qualitative and quantitative methods (Benjamin, Domine, \& Landine, 2001; Cairns, 2013, 2014; Corbett, 2007, 2009; Norman \& Power, 2015), each of these studies focused on only one research locale. The present study focuses on the aspiration narratives of young people from two distinctive communities in Western Canada. A comparative approach to youth's aspiration narratives offers us the opportunity to highlight particularity, and to discover convergences and variations (Azarian, 2011). 
International Journal of Child, Youth and Family Studies (2016) 7(3/4): 423-455

DOI: http://dx.doi.org/10.18357/ijcyfs73-4201616129

\section{Theoretical Framework}

\section{Bourdieu: Habitus, Capital, and Field}

Bourdieu described habitus as "a product of history" that constructs practices. It is the "active presence of past experiences" depositing schemes of thought, perception, and action in each organism (Bourdieu, 1990, p. 54). Thus, habitus operates at every single moment as "a matrix of perceptions, appreciations, and actions” (Bourdieu, 1977, p. 83). Youth from wealthy, white families within the Canadian context may have similar or overlapping habitus, which could be expressed through shared political views and social etiquette. It is important to appreciate that for Bourdieu, dispositions and lifestyles are not externally imposed, but work internally as people come to embody and reproduce them through their practices (Bourdieu, 1990). Bourdieu used the phrase "not for the likes of us" to describe how habitus shapes preferences and lifestyles, as a type of self-limiting force that circumscribes people's life choices (Bourdieu, 1984, p. 110). For example, a young person may subscribe to the belief that "people from my family attend (or do not attend) university", attributing educational choices to family and cultural traditions, but perhaps not recognizing how these opportunities are facilitated or limited by structures of social and cultural capital, and how such structures affect status and privilege.

Unpacking the conceptual relationship between habitus, capital, and field as Bourdieu conceived of it is important for understanding his views about the possibilities for social transformation (Reay, 2004). Using the metaphor of an "invisible playing field" that structures the nature of the game to be played, Bourdieu described fields as "area[s] of structured, socially patterned activity or 'practice", organized "around a body of internal protocols and assumptions, characteristic behaviors and self-sustaining values” (Terdiman, 1987, p. 806). For example, the field of adolescence can be described as a social arena that is constituted by the struggle for particular forms of capital — such as popularity among peers, physical attractiveness, and "coolness". The power of agents in a particular field is shaped by their habitus and access to capital (Gaventa, 2003, p. 9). Agents with various combinations of habitus and capital compete for power within a given field, and the logic of the field is thereby either reproduced or reconstituted. As Bourdieu described, change occurs when there is a mismatch or disjuncture between habitus and field (e.g., encountering a new field; Reay, 2004). Further, fields are only reproduced to the extent that the social actors within them are willing to accept the rules and to play along (Haines, Poland, \& Johnson, 2009). It is worth noting here that we are not conceptualizing each of the study sites as fields, but that each study site is constituted by multiple fields of practice (e.g., adolescent social spheres, home and family, school).

Bourdieu (1986) delineated several forms of capital and how these manifest within particular fields. In most fields, economic and cultural capital are considered the most important forms for structuring advantage, but social capital can also be central to acquiring status, based on one's ability to access and expand networks of relationships that facilitate opportunity. Bourdieu positions the different forms of capital as working in tandem: 
International Journal of Child, Youth and Family Studies (2016) 7(3/4): 423-455

DOI: http://dx.doi.org/10.18357/ijcyfs73-4201616129

A person's level of education, the cultural capital they possess, combined with the value of the networks on which it is possible for them to draw and the amount of economic capital at their disposal, gives a person certain advantages or disadvantages that structure their possible education and income. (Ashall, 2004, p. 23).

Similar to habitus, cultural capital is not transmitted instantaneously from parents to their children, but is described as an embodied state of what you know and can do (Stempel, 2005). Although cultural capital functions as a type of exclusion that limits the opportunities and mobility of lower-status and disadvantaged groups, those groups possess in their turn forms of cultural knowledge and capital that outsiders are not able to access.

Bourdieu's theory has been criticised for failing to account for the potential for people to “see their way out” of their habitus (Jenkins, 1992; Williams, 1995). For example, Alexander (1995) has argued that Bourdieu grants habitus undue power to determine social action (p. 140). However, according to Bourdieu's field notes, "rules are often bent or broken in practice” and the structure-over-agency argument does not necessarily apply "at the ground level where interests, desires, contingencies, and material exigencies all come into play” (Crossley, 2001, p. 83). What is typically neglected is that Bourdieu described habitus as having generative capabilities (1998, p. 8) and an inventive capacity (1990, p. 55). As Veenstra and Burnett (2014) have argued, although Bourdieu's theory of practice has been taken to task by many for being overly deterministic, that critique has most often been based upon a misreading of his relationalist perspective. Rather than drawing a "stark distinction between individual agency and social structure”, Bourdieu's theory of practice "consists of relations built upon relations” and "produces a representation of agency that is manifestly intersubjective in nature" (Veenstra \& Burnett, 2014, p. 188). In this schema, agency can be exerted "in fields to which the habitus is particularly attuned, where a person comprehends the shared set of opinions and beliefs of the field (doxa)" (Veenstra \& Burnett, 2014, p. 193). For instance, young people who challenge the androcentrism of school curricula understand that the set of opinions and beliefs of traditional educational domains is patriarchal; however, agency is exerted through their demands for more representation of non-normative and gender-diverse experiences and perspectives. At the “ground level”, rules can be "broken” and reconfigured (Crossley, 2001, p. 83) — altering the constitution of the field. In this scenario, the academic field could be reconstituted through a shift towards a more gender-inclusive curriculum.

\section{Bourdieu and "the Future"}

Also relevant to our analysis were Bourdieu's (2000) contributions in theorizing how people's longings for the future have been linked to processes of power:

The more power one has over the world, the more one has aspirations that are adjusted to their chances of realization, and also stable and little affected by symbolic manipulation. (p. 226) 
International Journal of Child, Youth and Family Studies (2016) 7(3/4): 423-455

DOI: http://dx.doi.org/10.18357/ijcyfs73-4201616129

The greater one's power, the more plausible one's dreams for the future become. Expanding on Bourdieu's theories about the transmission of capital, Jenkins (2002) has suggested that people normally opt for goals that make sense for their habitus; that is, they are likely to have aspirations that are similar to those of people with overlapping habitus (family members, those from similar cultural and class backgrounds), perhaps rendering their thoughts and choices about their futures predictable and unsurprising.

This model of the reproduction of future aspirations has been challenged by some scholars. For example, Gale and Parker (2015) contend that Bourdieu's explanations for the cultural and economic reproduction of capital are "too formal and static (i.e., structuralist)" (p. 84). Drawing from Appadurai (2004), they critique Bourdieu's theorization of aspirations for its over-preoccupation with the "sense of culture as pastness" and instead argue for a view of aspiration as a "navigational capacity" (p. 61), and more freedom from the "dominance of cultural habits and doxa" (p. 91).

Although we are mindful of these critiques, Bourdieu's theoretical framework provided a useful approach for analysing our narrative data on young people's aspirations. Although the participants' narratives suggested they were cognizant of their future opportunities as contextually reproduced and potentially constrained, their interviews also pointed to an "inventive capacity" that served as a navigational skill with which to "see their way out of" their habitus and their ostensibly predetermined social conditions.

In substantiating their use of Bourdieu's construct of habitus in their study on the aspirations of youth living in three communities in the United Kingdom, Allen and Hollingworth (2013) write:

Habitus can be understood to relate not simply to class-based dispositional understandings of what is thinkable for "people like me" but also for "people from round here”. We see young people's aspirations - their sense of where they belong — as being deeply entangled with their social and spatial location. (p. 501)

In a similar vein, we believe Bourdieu's theories offer a unique way of understanding young people's aspirations for the future since they allow us to consider young people's future orientations as "structured by objective conditions" - influencing youth to think of certain trajectories as undesirable and out-of-bounds and others as desirable and within reach — rather than through the lens of deficiency, which "holds young people responsible for their own (lack of) ambition and (im)mobility in education and work" (Allen \& Hollingworth, 2013, p. 500).

\section{Methods}

\section{Research Sites}

The qualitative data analyzed in this manuscript were collected for the Researching Adolescent Distress and Resilience (RADAR) study. This study involved extensive researcher 
International Journal of Child, Youth and Family Studies (2016) 7(3/4): 423-455 DOI: http://dx.doi.org/10.18357/ijcyfs73-4201616129

immersion or embeddedness in the participants' social context, drawing on ethnographic methods including individual interviews and field observations (Stage \& Manning, 2015). Five researchers from various academic backgrounds based in the School of Nursing at the University of British Columbia conducted interviews with youth over a span of two years (2012-2014) in three communities from distinct regions of British Columbia in order to explore young peoples' experiences of emotional distress and resilience. The research sites were selected for their distinct geographic, demographic, cultural, and other, characteristics.

This paper focuses on the insights of youth from the two most dissimilar of the three study sites in terms of demographics, culture, population size, city versus country traits, and other features. One of these is a small community in the northern part of the province, and the other, Vancouver, is a densely populated coastal city. In order to protect the confidentiality of participants from the smaller first community, we refer to it by a pseudonym, "the North".

The population of the North is approximately 4,800. This estimate includes those who live in the town and surrounding First Nations reserves and rural communities. The North's economy is primarily resource-based, with forestry, mining, and agriculture as its leading industries. According to 2011 Census statistics, which captured only population numbers in the town itself (excluding neighbouring communities and reserves), just over a quarter of the population self-identify as having an "Aboriginal identity" ${ }^{1}$, while the majority of the remaining population identify as coming from "European origins” (Statistics Canada, 2013). The community is located on unceded, traditional Indigenous territories.

In 2011, the population of Vancouver was approximately 600,300. It is embedded in a much larger metropolitan area with a population of over 2.3 million (Statistics Canada, 2012). Vancouver is a seaport municipality renowned for its forestry, film, and tourism industries. It is one of Canada's most ethnically and linguistically diverse urban centres. According to the 2011 National Household Survey Profile, "European Canadian" residents were the largest ethnic group in the city but comprised less than half the population (46.2\%), inhabitants of Chinese descent made up 30\% of the population, and those of South Asian descent comprised 6\% (Statistics Canada, 2013). The city of Vancouver is located on the unceded territories of the Musqueam, Squamish, and Tseil-Waututh peoples.

While these two cities are markedly distinct from one another, they share a common history of colonization, and in both contexts neocolonial state policies have continued to wreak havoc on the health and wellbeing of Indigenous communities. For example, health disparities continue to persist between this population and non-Indigenous populations in the province. Indigenous peoples are overrepresented in respiratory disease, diabetes, cancer, HIV/AIDS, mental health, and addictions statistics (First Nations Health Council, 2011, p. 21). While British Columbia — especially Vancouver — has often been characterised as having a culture that

\footnotetext{
${ }^{1}$ In British Columbia as a whole, Indigenous peoples make up approximately $5 \%$ of the population (Statistics Canada, 2011).
} 
International Journal of Child, Youth and Family Studies (2016) 7(3/4): 423-455 DOI: http://dx.doi.org/10.18357/ijcyfs73-4201616129

promotes "healthy” and “outdoorsy” lifestyles (Ellis, 2015; Ristovski-Slijepcevic, Bell, Chapman, \& Beagan, 2010, p. 319), this portrayal obscures the fact that there are high rates of income inequality and child poverty in the province. For instance, in 2012, one in five children in the province was living in poverty (First Call: BC Child and Youth Advocacy Coalition, 2014, p. 10), with particular populations of children over-represented in these numbers (First Call: BC Child and Youth Advocacy Coalition, 2013, p. 8). According to a 2013 report on child poverty in BC that drew on 2006 Census data, poverty rates were 48\% for status First Nations children and 28\% for other Aboriginal children, versus 17\% for non-Indigenous children (Macdonald \& Wilson, 2013, p. 17). An awareness of the overall demographics that describe the Indigenous population illuminates the apparent differences in the ways Indigenous and non-Indigenous youth discussed their futures. ${ }^{2}$

\section{Recruitment and Research Procedures}

Ethical approval for this study was acquired from the University of British Columbia Behavioral Research Ethics Board, and permission from the relevant school districts was acquired before interviewing young people. Given the sensitive nature of the study, and youth participants' rights to privacy and confidentiality, our ethics approval allowed for young people (aged 13 to 18) to provide their own consent to participate. Schools had the option of distributing a letter to parents informing them about the study. Prior to obtaining written consent, the interviewers reviewed the main points on the consent form with participants. Participants were paid \$20 CAD.

Recruitment efforts in the North included informational flyers posted in the local high school that directed interested youth to contact the project director. Youth were also recruited with the assistance of counsellors and teachers. In the North, 27 youth (14 women and 13 men) were interviewed; 16 participants were Indigenous, 4 were white, 4 were multiracial, 2 were Métis $^{3}$, and the racial heritage of 1 participant was unknown.

In Vancouver, participants were recruited with the assistance of school counsellors, who helped to identify young people from a diverse range of backgrounds. Of the 29 youth (14 women, 13 men, 1 "non binary identifying”, and 1 who intentionally left the gender information

\footnotetext{
${ }^{2}$ In the context of a different paper written on this study, we have explicitly addressed indigenous/non-indigenous relations, and the colonialism and racism that were pervasive in the northern community (please see Haines-Saah, Hilario, Jenkins, Ng, \& Johnson, 2016).

${ }^{3}$ Participants used the terms "Aboriginal", "Indian", and "First Nations" to describe themselves in the interviews. We have used "Indigenous" as an umbrella term for these identities. According to Linc Kesler, some consider Indigenous to be "the most inclusive term of all, since it identifies peoples in similar circumstances without respect to national boundaries or local conventions". While the term itself is not Indigenous "in the sense of deriving from an indigenous traditional practice or language ... it is very much a term that Indigenous people have worked hard to define" (n.d., para.17). One of the participants who identified as Métis said he belonged to a band in another province. It was not altogether clear whether the other participant who identified as Métis belonged to a Métis community or was using it colloquially to describe mixed white/Aboriginal heritage. However, she did say she did not belong to any bands in the community where she lives.
} 
International Journal of Child, Youth and Family Studies (2016) 7(3/4): 423-455 DOI: http://dx.doi.org/10.18357/ijcyfs73-4201616129

blank) who were interviewed, 16 were white, 5 multiracial, 3 Asian, 1 Latin American, 1 West Asian ${ }^{4}$, and 3 were of unknown racial identity or heritage. Interviews were recorded and subsequently transcribed; pseudonyms were used to protect the confidentiality of the participants. Interviews lasted anywhere between half an hour and two and a half hours, and were conducted in private rooms (e.g., empty counselling offices) in the school setting.

\section{Analytic Strategy}

Thematic analysis was used to systematically interpret and categorize our data from participant interviews. Aligned with our research focus on the influences of social context, our approach was informed by Wiles, Rosenberg, and Kearns (2005) who underscore the use of analytic strategies for "interpreting and understanding layers of meaning in interview talk ... a form of interpreting a conversation or story in which attention is paid to the embedded meanings and evaluations of the speaker and their context” (p. 90). To carry out the thematic analysis, after reading through multiple transcripts and becoming grounded in the data, the research team identified a preliminary coding scheme that covered the content of the interviews. The codes were exhaustive, but not mutually exclusive as they were applied to the data. In total, 15 codes were used to organize the data - Nvivo 10, a qualitative research software package, was used to highlight sections of the interview transcripts and then to sort the data according to the 15 codes. These included frequent topics from the interviews, such as peers and social connections, violence, coping strategies, and family. Data for this paper were extracted from the code, Aspirations and Goals. Aspirations and Goals captured young people’s stories of their future plans and their goals for adulthood. While there was no formal interview question regarding youth's prospects and thoughts about the future, the youth interviewed spontaneously raised this topic. Our research team also asked questions regarding "the future”, at times out of curiosity and at other times due to the organic flow of a particular interview. The Aspirations and Goals code was exported into a word processor document, which two members of the research team read through multiple times. Observations within this code were written into the margins of the document in order to determine the patterns and themes that were perceived to occur in the narrative data.

For each of the two sites, our readings of the narratives within the Aspirations and Goals code suggested four themes in the ways that youth discussed their future: (a) the family's role in shaping career and educational preferences, (b) perceptions of “opportunity”, (c) youth’s descriptions of their aspirations for change and mobility as seen through the notion of "elsewhere”, and (d) how some youth defied the narrative parameters mapped out by their peers and "saw a way out of" their habitus.

\footnotetext{
${ }^{4}$ We used the terms "Latin American" and "West Asian" as these are terms used in the Canadian census (Statistics Canada, 2015). "Latin American" in the Canadian census implies non-white, Latino-Latina identity.
} 
International Journal of Child, Youth and Family Studies (2016) 7(3/4): 423-455

DOI: http://dx.doi.org/10.18357/ijcyfs73-4201616129

\section{Findings}

\section{The North}

Family. What Bourdieu describes as the familial transmission of economic and cultural capital was unmistakably at work when we analyzed the participant narratives. Family relationships and circumstances appeared to be central to framing the habitus of young people in the North, whether young people were leaning towards the same life goals as older family members or trying to side-step them altogether.

Career aspirations in the North were focused on trades, art, and design, and professions such as nursing, rehabilitation, and social work. Two of the young men in this community spoke about wanting to follow the career paths of their fathers. Carl discussed wanting a job in carpentry or "mining with [my] dad." He elaborated, "My dad's working at [name of employer], he brings loads of plywood and all that to them. Yeah, it's pretty fun going and doing that with my dad ... At some points I go work with him.” Another young man’s desire to follow his father's career path was burdened by troubled family dynamics. Tony, a young Indigenous participant, discussed disobeying the vocational and life trajectory his mother desired for him a path that Tony felt too closely resembled his brother's - and pursuing his father's career path:

I don't know. Don’t feel like I was being good enough for my mom. Think she wanted me to be more like my brother .... We're ... just starting to get better 'cause she's finally realizing that ... that's not what I want to do in my life. I don't want to go to university. I don't want to be a doctor like him. I don’t want to be a ... physiotherapist. I just want to do something that I like and will ... for a long time. Like, my dad's worked in the bush since he was fifteen. Forty now. And he had his fun. He lived his dream.

Similar to Carl, Tony spoke of his aspirations to follow the professional ambitions of his father. Unlike Carl's situation, however, Tony and his mother had disagreed over whether this was the correct path.

One of the one young Indigenous women, Tori, discussed wanting to become a mechanic because "I used to watch my dad fix up cars and whatnot." She further explained:

I wanted to take [a mechanics program at school] but I don't know. I don't want to be stuck with a whole bunch of boys. I was already last year ... stuck with a whole bunch of guys, and I was, like, the only girl in there. It was kind of scary [laughs].

In this way, “traditional” gender stereotypes regarding appropriate career paths may also influence preferences and future aspirations, speaking to the nature of habitus as culturally and contextually embedded.

While a number of youth aspired to blue-collar jobs, two expressed a longing for something different. These desires, however, continued to reflect the accomplishments of family 
International Journal of Child, Youth and Family Studies (2016) 7(3/4): 423-455 DOI: http://dx.doi.org/10.18357/ijcyfs73-4201616129

members. Sonya, a young woman from an Indigenous background, stated a preference for attending a larger, acclaimed university outside of her hometown, and spoke about how several of her family members had studied there. While her mother and father did not attend this university, they, too, had acquired postsecondary education. Her desire to attend a postsecondary institution in general, and one specific university in particular, can be seen as an expression of her habitus: her desire for "higher learning” was implanted by her family’s ethos, which collectively viewed it as something of value and a realistic objective.

I've always wanted to go to [school 1].... my mum's brother went to [school 1] ... and he really likes it. And I like [school 1], and my Uncle M. went to [school 1].... two other of my family members went to [school 1]. Most of my family went to [school 1].... My mum went to [school 2] ... she went there for her childcare - I can't remember what it was, ECE.... She's right now the manager of the [local daycare], and my dad's a heavyduty mechanic at the [local mill].... Both my parents went to university and college.

Similar to Sonya, April's interview appeared to demonstrate a habitus oriented towards postsecondary education, as seen through her description of a relative's enthusiastic reaction after telling him she was considering attending the same small university in a larger city he had attended: "I told [my uncle] I was thinking about going to [the same school as he went to] I swear to God I thought he was going to start jumping."

For both of these young women, it appeared that family support for pursuing postsecondary education was a key influence on their trajectories, although this was described as resulting from a "modeling" effect rather than having been dictated to them by parents and family members; the preferences that these young people "absorbed" and assumed for their future paths were part of the context of their habitus. With the exception of Sonya and April, however, the career and life objectives discussed by youth in this community do not generally include an aspiration to attend university.

We also spoke to George, a participant of multiracial ancestry who, unlike those hoping to follow in the paths of family members, wanted nothing more than to diverge from the life trajectory of his abusive father. In order to remedy what he perceived to be the mistakes his father committed as a parent, he identified his life goal as becoming the father he never had:

He was physically abusing me and stuff and ... hurting me.... So I figured that he wasn't my dad and basically my whole entire life, my whole emotions, everything was based on my dad.... It's kind of hard because you kind of want a dad there, to teach me about things. But he’s just so stubborn. He can’t do it. Like, there’s just something about me that he hates. He just can't talk to me, just hates me.... That's the main emotional thing I have. It's the whole, whole reason I want, like, a son or a daughter, just so I could be there for them. 
International Journal of Child, Youth and Family Studies (2016) 7(3/4): 423-455

DOI: http://dx.doi.org/10.18357/ijcyfs73-4201616129

The aspirations described by this young man were outside the career or educational domains, and centred on establishing a stable family and becoming a parent much different from his own father. In regards to habitus, George's descriptions suggest that his priorities were fundamentally shaped by a "negative" social context and family environment in which he was raised, and that therefore the stability of having a loving family takes precedence. Young people's narratives in the North suggest that family members play an influential role — be it positive or negative - in shaping career, educational, and other future-related goals.

Opportunity. Youth's discussions about opportunities available to them suggested commonalities in their habitus. While a few Indigenous participants spoke about the shortage of opportunity in their communities, only one linked this to the history of racialized inequalities in the region. For example, when Christopher, a young Indigenous man, discussed the shortage of opportunities in his small town, he spoke about how place circumscribes aspirations, but also felt strongly about the value of individual effort and choice. Christopher's narrative speaks to the contradictory aspects of the habitus: on the one hand, he espouses the individualist model of success ("if you really, really try"), while on the other hand he is also aware of the limitations posed by the objective conditions of his circumstances ("opportunities in school, they're very slim"):

There's not too much opportunity in a small town, but if you really, really try, there's ... one famous guy from here.... But opportunities in school, they're very slim ... nothing too big, but you still get your chances, your little chances every now and then ... there's ... nothing really to do, and there's so much drug and alcohol abuse here that the kids ... if their parents are alcoholics or they do drugs or anything, they don't really have the strength to say no because they don't know how to say no.... [The kids] were never taught to have the strength to say no to that stuff, so a lot of them get into that. I have like, almost all my friends do it. I was not taught to say no. I kind of taught myself that because I have a goal. I have a career I want to follow, and that's the acting.

While Christopher spoke of inhabiting a field where people perceived substance use as a normal practice, he described how he managed to resist the temptation through an individualistic process of willpower and having a career goal, but without any mention of social or cultural capitals that may have facilitated his avoiding substance use.

The notion of community context as exerting a "negative" influence that spurns action was seen in the narrative of Abigail, an Indigenous participant, who spoke of wanting to stay in school because she had been made acutely aware of how unusual it is for members of her community to do so. One excerpt suggested Abigail's cognizance of the outcomes and the lack of opportunity for members of her community: "Just so many people around here always end up dropping out of school or staying here, and I don't want to do that. I want to get a good education.” Stacey, a young Indigenous woman who was pregnant with her first child pushed 
International Journal of Child, Youth and Family Studies (2016) 7(3/4): 423-455

DOI: http://dx.doi.org/10.18357/ijcyfs73-4201616129

this discussion around dearth of opportunity further by talking about how it is particularly felt for "Aboriginal” people such as she:

Mm, I like [living here].... I wish there was more opportunities to life and whatnot. Like, there is, but there's low chances of Aboriginals to succeed and whatnot.... 'Cause ... I'm Aboriginal ... I don't know. Like, it's, like, really hard and ... I still try to ... put myself in gear ... 'cause I want to succeed in life ... for my baby.

The history of colonization and collective history of trauma experienced by Indigenous communities may have influenced her perceptions of the future and the future of those living in her community. In this social context, rather than early pregnancy being seen as a disadvantage, succeeding at parenthood and as a provider for one's children was seen as one of the few positive future options available. These narratives speak to the need to understand habitus as exerting both a "positive" and "negative" social influence, with age-specific dimensions that shape life choices and perceptions of the future.

Mobility and the notion of elsewhere. Narratives from young men and women in the North suggested differing expressions of habitus as seen through their descriptions of mobility and the idea of moving elsewhere. Perhaps due to the perceived shortage of opportunity that existed in their community, several of the young men indicated that it would be necessary for them to leave their community to further their careers in a larger, urban centre like Vancouver.

In contrast, some young women in the North conveyed their reluctance, and in a few cases, fear, of moving to the "big city". This dissimilarity may also speak to the influence of habitus - in terms of how unspoken and gendered expectations shaped the ambitions of young people in the context of a small town such as the North. There were several examples of narratives where young women (white, Indigenous, and multiracial) struggled with the idea of leaving home and saw drawbacks to living in the city. For example when discussing moving from the North to a city such as Vancouver, April, a young white woman, was clear that the idea of living in a city was outside the confines of her habitus: "I've been there - that place is too big for me! Do you see where I’m from? [Vancouver] scares me.” Vivian, a young multiracial woman, and Libby, a young Indigenous woman, echoed these ideas about the city:

I know for one thing I'm never going to live in a city. If it's not [this town], it's going to be another small town. There's something about small towns. It's a good feel.... I don't know what it's like in big cities either, so I may not — I might like it. I don't know. But two days on concrete, and I can’t stand it. (Vivian)

I'm thinking [name of small city] for now, just so it's a little bit ... closer to home. So I'm not, like - if I get scared, or if I freak out that I'm, like, on my own or something, then I'm not too far away from home. (Libby) 
International Journal of Child, Youth and Family Studies (2016) 7(3/4): 423-455

DOI: http://dx.doi.org/10.18357/ijcyfs73-4201616129

For Vivian and Libby, feeling "at home" did not necessarily mean staying exactly where they were raised, but it did denote the social context of a smaller place and suggested that they embodied a habitus that was attuned to the specificities of small-town living.

Like some of her female peers, Stacey, a young Indigenous woman, expressed trepidation about living in a bigger centre. However, she appeared to feel that the sacrifice of living in an unfamiliar setting was "worth it" because staying at home would limit opportunities for success and advancement:

[Leaving] kind of freaks me out 'cause I've been living in such a small town for the longest time. Everyone knows everyone. So it's ... kind of freaky to go somewhere else and ... somewhere big and start off new and where you don't know no one.... But ... I would say it's ... worth it because you can't just sit around on your butt all day, all year and then ... all your life....I was thinking ... if I get a fashion degree, I would like to start up ... my own clothing store in [community 1], I mean, yeah, [community 2].

Thus, unlike those who expressed the desire to remain in town after high school, Stacey seemed to consider this immobility a failure not of opportunity but of individual choice. This suggests the complexities of the habitus at work in how youth perceive their future aspirations and picture their future identities, in terms of the tension between the narrative of the limiting structure (lack of opportunity) and a narrative of individual achievement (lack of agency or will-power).

It is worth emphasizing what may be seen as the gendered aspects of habitus: in this case, there were differences in narratives of mobility; young women in the North expressed doubt about leaving behind their small town origins, and young men did not.

\section{Vancouver}

Family. In Vancouver, when youth wanted to model careers after the adults in their lives, these careers tended to be jobs that were higher paying and recognized by upper-middle- and middle-class families as "good" jobs. In Vancouver, most youth who discussed careers anticipated a future involving professions such as business, sciences, law, engineering, and the health sector. A number of young men in both locations modeled their dreams for the future after their fathers. One young white man, Scott, talked about wanting to go into business and credited his father for influencing this goal: "So, like, my dad, he's always talking on the phone.... I get to listen in on it, so I know a lot more than other kids do about [the stock market] ... yeah, businesses and everything." Scott's narrative suggests very clearly how capital is transmitted through the family as he attributed his knowledge and interest in the financial industry to his father. His narrative illustrated the pre-reflexive or taken-for-granted aspects of how habitus is transmitted through families as Scott learned about his father's professional practice through an indirect transfer of knowledge. 
International Journal of Child, Youth and Family Studies (2016) 7(3/4): 423-455 DOI: http://dx.doi.org/10.18357/ijcyfs73-4201616129

There were additional examples of the importance of family members in helping youth navigate their futures. One young white woman, Helena, discussed being thankful for her brother's assistance in familiarizing her with the university system and its entry requirements:

Having my brother there being like "you need to take this just to keep your options open" a lot of kids didn't have that older brother or older sibling to guide them.... I was obviously really grateful of him being like that, 'cause if I didn’t have - I wouldn't have taken Physics and Chem 11 if I didn't have my brother be like “do this”. I wouldn’t have been able to get into the program that I want to now.

Helena was conscious of the advantages she had as a result of having a savvy, experienced older brother - something she was aware that her peers might not have. Her experience was demonstrative of habitus as rooted in capital and field: through her brother's knowledge (cultural capital) of the postsecondary school system and its bureaucracy (field), a field-specific transmission of capital took place.

Like Tony from the North, who wanted to follow the career path of his father in spite of his mother wishing him to follow in his brother's footsteps, the future plans of Gen, a young man of multiracial heritage in Vancouver, also appeared to be informed by the longstanding tensions in his relationship with his mother:

I never really liked doing things, I was lazy. When I do things, I do 100 percent but, when I don’t, it’s just “ooh, I wanna sleep”. But, yeah, my mom, she always promised me the business, she was saying, "Okay you're gonna do this, this, this” and then that's what I was studying for, when I was little, that's what I had in my dreams. I had everything set on that, and recently they said, “no, can’t do that.”

Thus while a number of the young men we interviewed in this study discussed wanting to follow the career paths of their fathers, both Tony and Gen rebelled against their mother's expectations of them. In Gen's situation, his mother would only allow him to take over the family business if he attended university. While he was in favour of the former, the idea of attending university did not appeal to him. This example perhaps suggests that being socialized into a particular habitus - and the process of rejecting the future path associated with this - is a common process for youth, despite the fact that Tony and Gen inhabited very different fields with different forms of capital in play.

Opportunity. A number of young women and young men from Vancouver had perceptions about their futures that were notably optimistic. One theme that emerged from these interviews involved a shared perception of the limitlessness of choice, which was manifest in youth's comments on education and career. For example, Helena's narrative brimmed with confidence when discussing the number of professional doors open to her; furthermore, she took 
International Journal of Child, Youth and Family Studies (2016) 7(3/4): 423-455

DOI: http://dx.doi.org/10.18357/ijcyfs73-4201616129

for granted that her chosen career will coincide perfectly with her personal passions, an indication of her economic and cultural capital:

There's still so many options of things that I could do, and things that I've had interests, like I like city planning, I love law, I'm taking law right now. But like, for me, my passion’s always been sports. Passion’s always been like physical education. I could be a gym teacher, a physio, I can be a nurse. I love helping people.

Joseph, a young white man, also spoke about the post-secondary opportunities available to him. His narrative illustrates how deeply rooted and taken for granted his views on attending postsecondary school were; the notion of not attending university did not figure in his narrative:

I'm in the process of trying to decide where I'm going to go, there's [university 1], [university 2], and [university 3].... It was a big decision here for me to where it's like, say [university 3]'s the school where I'd like to go to the most, but it's not the program I’d like.

Unlike her peers who may have had little doubt that they could achieve their desired goals, Reilly, a young white woman, conceptualized the possibility — albeit only to a slight degree — that things might not go in the way she intended:

I like Sciences, so getting into Sciences, especially [university 4], I know is pretty hard.... I like Marine Biology but I'm not set on that one thing, it's not like one thing I wanna do. So I'm kind of keeping my options open, so I haven't really put pressure on myself yet. Not sure if I will [chuckles] maybe a little bit, but ... if Sciences doesn't end up working out then I'll always go in for Arts, or set building and special effects, sports, I have lots of options open right now.

For Reilly, the failure to get into postsecondary schooling still falls outside the range of every one of these possibilities.

Mobility and the notion of elsewhere. Perceptions of the future among Vancouver participants tended to be "mobile" and "outward" for both the men and the women. For those who wanted to stay in their communities, postsecondary education was, with few exceptions, part of their future plans. The young women we interviewed in Vancouver had no hesitation about leaving their community. For instance, Gabby, a participant of multiracial background, talked about how she had been accepted to a prestigious school in Eastern Canada, and how she would be studying there the following year: "I'm excited. Sounds hard, but you know, I'm ready for it I think.” In other narratives it was apparent that economic and cultural capital were in play in facilitating mobility, as Ling, a young Asian man who identified as an international student from China studying in Vancouver, described: 
International Journal of Child, Youth and Family Studies (2016) 7(3/4): 423-455

DOI: http://dx.doi.org/10.18357/ijcyfs73-4201616129

Basically my parents think they have sacrificed too much to let me live in Canada. My mother sacrificed his [sic] group, his friends, China, my father, my father wants to live with us but he cannot, he has work in China, and that's really essential for us. So, all they want is for me to get brighter future, specifically go to a better university in this case, so they assign me a lot of study objectives like tasks.

Not all youth in Vancouver expressed a desire to leave home. A few expressed varying degrees of interest in living locally or within the province after high school graduation. Unlike many youth in the North, however, postsecondary education was usually among their goals. Youth expressions of aspiration in Vancouver suggested a habitus of privilege, in that the freedom of mobility and the "limitlessness" of possibility appeared to be narratives that had come to be taken for granted.

\section{“Seeing a Way Out" of Habitus}

While there were types of professional and academic pathways that youth from each region typically chose, there were other expressions of ambition that illustrated the influence of fields outside the academic context. Within these social fields, different social logics, practices, and currencies were in play. Because examples that seemed to demonstrate youth seeing a way out of their habitus were limited in each study site; we represent findings from both communities in this section.

In the North some students discussed vocational prospects that many would construe as "unrealistic" or "impractical”; in other words, what they coveted would be highly improbable for anyone, regardless of their social, economic, and cultural positioning. George, a young man of multiple racial ancestries, talked about becoming a "rap star", while Tyson, a young Indigenous man, mentioned "professional wrestling and singing" as two plausible career paths. Specific to the field of adolescence, future goals that are not based on real life experience may be common.

In Vancouver, Gen's future-related discussion contrasted with the "can-do" attitudes of some of his peers, many of whom appeared to have dreams that were clearly defined. He suggested that while he would attend university, he wanted his mother to understand that she needs to "just give me time to think about what I wanna do. Because I have no idea what I want to do.” Gen's behaviour fell outside the norms of “acceptable” adolescent behaviour in his community, especially when viewed from the perspective of adult authority such as parents and teachers. His perceptions might suggest a logic specific to the field of adolescence as a developmental stage. From this developmental view, adolescent habitus should not always be associated with having a concrete and practical future orientation. Given the emphasis his high 
International Journal of Child, Youth and Family Studies (2016) 7(3/4): 423-455

DOI: http://dx.doi.org/10.18357/ijcyfs73-4201616129

school placed on postsecondary education ${ }^{5}$, Gen's approach to the future fell outside the logic of practice envisioned as appropriate for him given his habitus and family background.

Like Gen, Benjamin, a young white man, expressed feelings of uncertainty towards his future. The one objective he had was to "grow weed [for the government]", which was less traditional and distinguished his aspirations from the more conventional career goals of his peers:

I'm a teenager. I don't know what I wanna do with my life right now, but, one thing I wanna do in the future is grow weed for the government. Like I know how to grow weed, I've grown weed before, it's easy, it's as easy as growing a plant, and you can make a lot of money growing pot, a lot. So easy [chuckles] and you don't have to go to school to grow weed, that's why, that's what I grew up knowing to do, and that's what I probably will do.

To aspire to a career of growing state-sanctioned marijuana is not an implausible objective given the context of Canada where medicinal marijuana has been legalized, and British Columbia, where cannabis is widely used, but this was clearly still far from a socially conventional career choice. What was also gleaned from his interview, however, was that this young man grew up in a part of the province where cannabis use was relatively common and accepted. Given this information, it would appear that his desire to cultivate cannabis for a future living made sense for him. Like Gen, he may have been inhabiting a field of social practice specific to adolescence; specifically, a logic in youth culture that endeavours to rebel against the "straitlaced" ethos of mainstream adult culture.

\section{Summary and Comparison of Themes}

In both locales, immediate and extended family members appear to have played a considerable role in shaping youth's preferences for their academic and professional futures. However, while many participants noted the instrumental role family members played in positively influencing their aspirations, two youth also discussed having goals that challenged their relationships with their parents. In this vein, fraught familial ties also appeared to shape the habitus.

It also appeared that the opportunities youth felt were available to them varied greatly between the two locations. In the North, youth — particularly the Indigenous participants observed the dearth of options available to them, and commented on the common hurdles young people had to navigate in this community on a daily basis. In Vancouver, an altogether different habitus was suggested through the narrative findings. For example, none of the youth talked about shortages of opportunity.

\footnotetext{
${ }^{5}$ This was evidenced by the strong presence of university recruitment material at his school, which was posted on bulletin boards.
} 
International Journal of Child, Youth and Family Studies (2016) 7(3/4): 423-455

DOI: http://dx.doi.org/10.18357/ijcyfs73-4201616129

Narratives of mobility in the North appeared to take on a gendered dimension; young women expressed their reluctance to move away from the small town environment and into a larger community, while young men did not. Youth in Vancouver had dreams for the future that more often entailed moving to other centres; a fear of moving was largely absent from these narratives. In fact, attitudes towards leaving home often took the shape of eager anticipation of what lay ahead.

Seeing a way out of habitus - young people dreaming outside the narrative boundaries of their peers - was a theme also seen in the data, particularly in young men's narratives. In the North, this creativity was expressed as the desire to become something unusual and perhaps unlikely (rap star, professional singer, or wrestler). In Vancouver, this took the form of some participants thumbing their noses at parental and adult expectations (not having a clear sense of what they wanted for their future, wanting to grow cannabis for a living).

\section{Discussion}

\section{Study Contributions}

Our analysis of the findings suggests insights for the youth aspirations literature in general, and in particular for Bourdieusian-informed approaches that deploy habitus as a way to understand how socio-structural conditions shape young people's trajectories for better or worse.

By employing a Bourdieusian perspective, we explored the aspirations youth hold for their adulthoods and considered how these narratives may be interpreted as the products of an "adolescent” habitus, influenced by social fields beyond family-based markers of capital and social advantage. Although his work did not explicitly address adolescence as a distinct category of habitus, we have argued that Bourdieu's theorization of habitus, capital, and field can be extended to do so, and is useful for exploring how social context shapes youth perceptions of the types of futures that are possible and achievable. Indeed, although Bourdieu argued that people from similar habitus held common views regarding "what is not for the likes of us", a few young people preferred to distinguish themselves from the family or the community with whom they perceived they were expected to share a habitus by pointing out that the dispositions that currently composed it were not "for the likes of them", as individuals. In Bourdieusian terms, this narrative reflected these individuals' "inventive capacity" — their ability to see their way out of the circumstances they felt were represented in the experiences of their peer group.

It is also worth considering the potential limitations of Bourdieu's theorization when applied to our contemporary research context, particularly how his concepts might need to be supplemented and adapted to account for the range of youth experiences represented in our findings. For instance, youth culture scholars and others have adapted the idea of cultural capital and suggested that an adolescent-specific form of "subcultural capital" is useful for addressing the types of cultural currencies that operate in the context of youth cultures. Similar to lifestyle markers that denote upward mobility and class status, subcultural capital facilitates "coolness" 
International Journal of Child, Youth and Family Studies (2016) 7(3/4): 423-455 DOI: http://dx.doi.org/10.18357/ijcyfs73-4201616129

and success for youth outside the markers of adult preferences and lifestyles (Thornton, 1996). This subcultural capital may have played a role in shaping the narratives of a few of our participants who discussed wanting careers that did not conform to typical working- and middleclass ideals (marijuana grower, rap artist, wrestler). Further, there was a gendered dimension to this subcultural capital in that all of the participants who expressed these types of aspirations were young men. These young men inhabit a gender-specific field of adolescent subculture that espouses rebellion.

In their investigation into the aspirations of youth living in disparate parts of the United Kingdom with regard to the "knowledge economy", Allen and Hollingworth (2013) argued that "social class can produce a stickiness which mediates how subjects inhabit place.... Some subjects, through their spatial and social location, can embody mobility and weightlessness while others remain sticky" (p. 502). These authors deployed the notion of class in their research in relation to how participants defined themselves, parental occupation, and family history of education, in addition to conceptualizing it as a social category that is "dynamic and always in process" (p. 503). Similarly, youth living in Vancouver pictured themselves as more mobile and weightless, ready to move further and more often than those youth living in the North. For the most part, Northern participants' ideas of their future selves remained rooted in their original communities; in the words of Allen and Hollingworth, these youth's aspirations "remain sticky".

Adding to Allen and Hollingworth's (2013) findings regarding place-based social class, this study demonstrated the ways that gendered and racialized distinctions also exert an influence on how young people conceive of mobility, and where they plan to be in the future.

Undoubtedly, the geography and the culture of small towns may foster the idea that urban living is intimidating and undesirable. In the North, young women in particular deemed the "big city" to be a daunting place. In a number of cases, they felt that contact with this particular setting should be kept to a minimum, or avoided altogether. This was one example of how habitus suggests socially-embedded and unchallenged dimensions of (gendered) practice that shape narratives about future opportunities and mobility. Gender is an embodied social category that shapes the perceptions of young women both in terms of their future aspirations and their everyday practices of "taking up space" in the social fields that comprise their community. However, this wary attitude towards living in other places was not expressed in the young women's narratives in Vancouver, which suggests a stronger influence of gender norms in the smaller community.

A few Indigenous participants in the North discussed how opportunities for youth in their communities were circumscribed, yet, these same young people's narratives represented the voices of youth who were able to use their navigational capacity to see their way out of their habitus. Of these young people, only one woman identified these particular circumstances as being racialized, by alluding to reduced opportunities for Aboriginal people. On the other hand, the influence of race did not appear in young people's discussions about opportunity in Vancouver. This could suggest that racial inequalities between white and racialized youth in 
International Journal of Child, Youth and Family Studies (2016) 7(3/4): 423-455

DOI: http://dx.doi.org/10.18357/ijcyfs73-4201616129

Vancouver are not as stark as inequalities between white youth and Indigenous youth in the North.

\section{Study Limitations}

While the findings speak to broad differences between the narratives of youth from the North and from Vancouver, they are limited in that they are not illustrative of all young people in these two communities. As participants were chosen from one high school in each community, youth who were not attending school at the time of the study were not represented. Given the small population size in the North, it only has one high school; however, in Vancouver, drawing participants from only one high school means that the socioeconomic and racial backgrounds of the Vancouver participants do not represent a cross-section of the city. The secondary school where we interviewed in Vancouver was located in a relatively privileged catchment area. While the students at this school did not represent a socioeconomic monolith, interviewing young people at a school in a more socioeconomically disadvantaged area of the city may have elicited narratives that had more in common with the voices of youth from the North.

Critically informed qualitative research demands attention to the power imbalances between researchers and participants that are inherent in every research process (Karnieli-Miller, Strier, \& Pessach, 2009). While this does not mean power is one-directional, given that there are moments when participants themselves can assert power, researchers working within traditional scholarly paradigms ultimately have greater power to influence how findings are collected, interpreted, and shared. Therefore when considering the limitations of this study we have considered how these dynamics may have influenced our interpretation of the findings. For example, young people who perceived their interviewers as women from educated, privileged backgrounds may have responded in ways they felt would suit their interviewers' expectations (e.g., self-censoring based on not wanting to cause offence).

\section{Study Implications}

The differences in youth's habitus between sites, and the distinctions in their aspirations, class, race, and gender, speak to the importance of utilizing locally derived and tailored strategies for improving young people's educational pathways and future trajectories. In other contexts, it has been suggested that shifting attention to aspirations-focused policy development for youth would be helpful. In the United Kingdom, for instance, education policy (see Department for Children, Schools, and Families, 2009) has targeted aspirations as an area of concern for young people, and has viewed aspirations-focused policies as crucial to elevating attainment, employability, and social mobility in this population (see Spohrer, 2011). Critics of these educational policies, such as Allen and Hollingworth (2013), have argued that these strategies are "socially and spatially restrictive” (p. 500), and have an asymmetrical impact on young people depending on their social class and geographical locations, among other factors. Likewise, in our findings, youth's narratives in the North suggested a poverty of opportunity. Yet these findings also demonstrated that many youth living in the North wished to stay home or 
International Journal of Child, Youth and Family Studies (2016) 7(3/4): 423-455

DOI: http://dx.doi.org/10.18357/ijcyfs73-4201616129

close to home. In this context, creating and supporting local educational and employment opportunity could have a lasting impact on their wellbeing. Such home-grown approaches would be better able to accommodate racial, class, and gender differences (i.e., socially produced forms of advantage and disadvantage) than policies that do not attend to young people's dissimilar habitus, as have been enacted in some parts of the world, including the United Kingdom. Locally designed programs would be more attuned to regional experience given their geographic proximity and use of local expertise.

There is a need for interventions that extend beyond the school to the home, through the inclusion of parents and other family members, as well as to the larger community. Theatre of the Oppressed (Brecht Forum Archive, n.d.) from Brazil is an example of an educational tool that can be used by youth, parents, and other family members. Theatre of the Oppressed "is a form of popular community-based education that uses theater as a tool for social change", and is based on Augusto Boal's work with impoverished people and workers in Latin America (Mandala Center for Change, n.d.). The topics covered in this "participatory theatre" forum (Brecht Forum Archive, n.d.) have included what youth imagine for their futures, among other themes (Mandala Center for Change, n.d.). As for community level interventions, one example of a promising initiative for Indigenous youth is the Gathering Our Voices Aboriginal Youth Conference hosted annually by the British Columbia Association of Aboriginal Friendship Centres (n.d.). This event gathers young people from across British Columbia to explore educational and career opportunities, learn new skills and ideas, and share knowledge through cultural activities.

While most of the young people interviewed in Vancouver expressed what would qualify in mainstream discourse as a healthy level of aspiration - setting their sights on a postsecondary education and going on to well-paying upper-middle- or middle-class careers - there were some whose narratives did not correspond with conventional expectations. Even when young people are ostensibly surrounded by opportunity, local government policies aimed at boosting aspirations in this group must recognise the significance of these variant narratives, and, furthermore, not stigmatize, or relegate to the status of "lost cause", individuals who have unorthodox perceptions about their futures.

Local government policies could begin by broadening existing definitions of what qualifies as a desirable future-oriented outlook, and by calling into question current assumptions about what constitutes a successful civic subject. Putting this into practice could mean expanding the range of postsecondary and vocational opportunities available to young people, thereby easing the pressures upon them to aim for particular, narrowly construed forms of excellence.

\section{Directions for Further Research}

This area of research warrants further exploration into how existing literature frames youth's aspirations. To begin, we might ask, "How are definitions of success narrowly construed in this literature?”, and “Are these definitions extensions of researchers' social locations and 
International Journal of Child, Youth and Family Studies (2016) 7(3/4): 423-455

DOI: http://dx.doi.org/10.18357/ijcyfs73-4201616129

positions of privilege?” As Allen and Hollingworth discussed in their 2013 study, the notion of mobility is often bound up with success and a middle-class cosmopolitanism, while the notion of not leaving home is often bound up with failure and a shortage of ambition. What unconscious biases pervade mainstream discourse around youth and their achievement of future success? While initiatives that encourage youth aspirations should account for differences in habitus and not make assumptions about what constitutes success, there should also be an awareness of structural barriers and inequalities that contribute to uneven and disparate levels of aspiration among populations with differing habitus. Other future research directions could involve examining the ways government policies have attempted to manage and direct youth aspirations. This would be valuable in guiding future action aimed at expanding youth-driven conceptualizations of what constitutes success.

The findings suggest some directions for gender-specific research comparing aspirations of young women and young men through a Bourdieusian lens. The narratives suggested that many young women in the North do not feel safe enough to leave home after high school for educational and employment pursuits; this may speak to specific gendered and racialized structural barriers for young Indigenous women in this part of the province. For instance, what was perhaps unspoken in these narratives was the influence of local and structural conditions of violence against Indigenous women in and around northern British Columbia, in particular what is known as the "Highway of Tears". This section of Highway 16 stretches across several communities in northern British Columbia (including the North); dozens of women, many of them Indigenous, have been abducted and murdered along this highway, and many are still missing with cases unsolved (Rhoad, 2013). While the young women themselves did not name the Highway of Tears as a reason to stay in town, the issue of mobility and violence against women needs further exploration. Research that explores young women's narratives about their futures through a critical gender and place-based lens would help address this need. In this capacity, Bourdieu's (2001) conceptualization of gendered, symbolic violence as a feature of habitus (the pre-reflexive and taken-for-granted conditions that create the context for actual violence) would provide a useful way for considering this apparently gendered distinction that emerged in our study.

\section{Conclusion}

While his conceptual framework did not explicitly theorize about adolescent-specific capital, we found the application of Bourdieu's theories on habitus, capital, field, and "the Future” helpful for exploring youth narratives about their aspirations. The sheer variation in youth's stories suggests that far from being reflections of their "innermost selves and desires", young people's narratives about the future underscore the ways structural inequalities - founded on disparities based in class, culture, race, gender, and place — have "gotten inside their heads". Policy makers who ignore these differences in habitus will continue to do so at youth's peril. 
International Journal of Child, Youth and Family Studies (2016) 7(3/4): 423-455

DOI: http://dx.doi.org/10.18357/ijcyfs73-4201616129

\section{Acknowledgments}

The authors would like to thank the youth who generously offered their time and insights to the study upon which this manuscript is based. The RADAR Project was funded by a grant from the Canadian Institutes of Health Research (CIHR MOP-120776). 
International Journal of Child, Youth and Family Studies (2016) 7(3/4): 423-455

DOI: http://dx.doi.org/10.18357/ijcyfs73-4201616129

\section{References}

Abada, T., Hou, F., \& Ram, B. (2008). Ethnic differences in educational attainment among the children of Canadian immigrants. Sandbox Journal for CanJSoc, 34(1), 1-30.

Alexander, J. (1995). Fin de siècle social theory: Relativism, reduction and the problem of reason. London, UK: Verso.

Alexander, K. L., \& Eckland, B. K. (1974). Sex differences in the educational attainment process. American Sociological Review, 39(5), 668-682.

Allen, K., \& Hollingworth, S. (2013). “Sticky subjects” or “cosmopolitan creatives”? Social class, place and urban young people’s aspirations for work in the knowledge economy. Urban Studies, 50(3), 499-517. doi:10.1177/0042098012468901

Aman, C., \& Ungerleider, C. (2008). Aboriginal students and K-12 school change in British Columbia. Horizons 10(1), 31-33.

Appadurai, A. (2004). The capacity to aspire: The culture and terms of recognition. In V. Rao \& M. Walton (Eds.), Culture and public action (pp. 59-84). Stanford, CA: Stanford University Press.

Archer, L., \& Yamashita, H. (2003). “Knowing their limits”? Identities, inequalities and inner city school leavers’ post-16 aspirations. Journal of Education Policy, 18(1), 53-69. doi:10.1080/0268093032000042209

Ashall, W. (2004). Masculine domination: Investing in gender? Studies in Social and Political Thought, 9(2), 21-39.

Azarian, R. (2011). Potentials and limitations of comparative method in social science. International Journal of Humanities and Social Science, 1(4), 113-125.

Ball, S. J., Macrae, S., \& Maguire, M. (1999). Young lives, diverse choices and imagined futures in an education and training market. International Journal of Inclusive Education, 3(3), 195-224. doi:10.1080/136031199285002

Behnke, A. O., Piercy, K. W., \& Diversi, M. (2004). Educational and occupational aspirations of Latino youth and their parents. Hispanic Journal of Behavioral Sciences, 26(1), 16-35.

Benjamin, A., Domene, J., \& Landine, K. (2001). Constructing the future in the liminal spaces between adolescence and adulthood: Responsibilities, careers, and social contexts. The Canadian Journal of Career Development/Revue canadienne de développement de carrière, 13(1), 47-58. 
International Journal of Child, Youth and Family Studies (2016) 7(3/4): 423-455

DOI: http://dx.doi.org/10.18357/ijcyfs73-4201616129

Bourdieu, P. (1977). Outline of a theory of practice (R. Nice, Trans.). Cambridge, UK: Cambridge University Press.

Bourdieu, P. (1984). Distinction: A social critique of the judgment of taste (R. Nice, Trans.). Cambridge, MA: Harvard University Press.

Bourdieu, P. (1986). The forms of capital. In J. Richardson (Ed.), Handbook of theory and research for the sociology of education (pp. 241-258). New York, NY: Greenwood Press.

Bourdieu, P. (1990). The logic of practice (R. Nice, Trans.). Stanford, CA: Stanford University Press.

Bourdieu, P. (1998). Practical reason: On the theory of action. Stanford, CA: Stanford University Press.

Bourdieu, P. (2000). Pascalian meditations (R. Nice, Trans.). Stanford, CA: Stanford University Press.

Bourdieu, P. (2001). Masculine domination (R. Nice, Trans.). Cambridge, UK: Polity Press.

Bourdieu, P., \& Passeron, J. C. (1977). Reproduction in education, society, and culture. London, UK: Sage.

Bourdieu, P., \& Wacquant, L. J. D. (1992). An invitation to reflexive sociology. Chicago, IL: University of Chicago Press.

Bowden, M. P., \& Doughney, J. (2010). Socio-economic status, cultural diversity and the aspirations of secondary students in the western suburbs of Melbourne, Australia. Higher Education, 59(1), 115-129.

Bowden, M. P., \& Doughney, J. (2012). The importance of cultural and economic influences behind the decision to attend higher education. The Journal of Socio-Economics, 41(1), 95103.

Brecht Forum Archive. (n.d.) Augusto Boal and the Theater of the Oppressed. Retrieved from brechtforum.org/abouttop

British Columbia Association of Aboriginal Friendship Centres. (n.d. ) Gathering Our Voices. Retrieved from http://www.bcaafc.com/newsandevents/gathering-our-voices

Cairns, K. (2013). The subject of neoliberal affects: Rural youth envision their futures. The Canadian Geographer/Le Géographe canadien, 57(3), 337-344. doi:10.1111/cag.12012

Cairns, K. (2014). Both here and elsewhere: Rural girls' contradictory visions of the future. Gender and Education, 26(5), 477-489. 
International Journal of Child, Youth and Family Studies (2016) 7(3/4): 423-455

DOI: http://dx.doi.org/10.18357/ijcyfs73-4201616129

Ceballo, R. (2004). The influence of neighborhood quality on adolescents' educational values and school effort. Journal of Adolescent Research, 19(6), 716-739. doi:10.1177/0743558403260021

Charlesworth, S. J. (2000). A phenomenology of working-class experience. Cambridge, UK: Cambridge University Press.

Corbett, M. (2007). Travels in space and place: Identity and rural schooling. Canadian Journal of Education, 30(3), 771-792.

Corbett, M. (2009). No time to fool around with the wrong education: Socialisation frames, timing and high-stakes educational decision making in changing rural places. Rural Society, 19(2), 163-177. doi:10.5172/rsj.19.2.163

Crossley, N. (2001). The phenomenological habitus and its construction. Theory and Society, 30(1), 81-120. doi:10.1023/A:1011070710987

Crysdale, S., King, A. J. C., \& Mandell, N. (1999). On their own? Making the transition from school to work in the information age. Montreal, QC \& Kingston, ON: McGill-Queen's University Press.

De Graaf, N. D., De Graaf, P. M., \& Kraaykamp, G. (2000). Parental cultural capital and educational attainment in the Netherlands: A refinement of the cultural capital perspective. Sociology of education,73(2), 92-111.

Department for Children, Schools and Families. (2009). Quality, choice and aspiration: A strategy for young people's information, advice and guidance. .Norwich, UK: The Stationery Office.

Domenico, D. M., \& Jones, K. H. (2006). Career aspirations of women in the 20th century. Journal of Career and Technical Education, 22(2), 2-7.

Donnelly, M., \& Evans, C. (2015). Framing the geographies of higher education participation: Schools, place and national identity. British Educational Research Journal, 42(1), 14693518.

Dumais, S. A. (2002). Cultural capital, gender, and school success: The role of habitus. Sociology of Education, 75(1), 44-68.

Ellis, E. (2015, August 20). If everyone was as healthy as people in B.C., Canada would save billions. The Vancouver Sun. Retrieved from http://www.vancouversun.com/health/everyone+healthy+people+Canada+would+save+billi ons/11295538/story.html 
International Journal of Child, Youth and Family Studies (2016) 7(3/4): 423-455

DOI: http://dx.doi.org/10.18357/ijcyfs73-4201616129

Empey, L. T. (1956). Social class and occupational aspiration: A comparison of absolute and relative measurement. American Sociological Review, 21(6), 703-709.

Evans, C. (2016). Moving away or staying local: The role of locality in young people’s 'spatial horizons' and career aspirations. Journal of Youth Studies, 19(4), 501-516. doi:10.1080/13676261.2015.1083955

Finnie, R., Lascelles, E., \& Sweetman, A. (2005). Who goes? The direct and indirect effects of family background on access to post-secondary education (Analytical Studies Branch Research Paper Series, No. 237). Ottawa, ON: Statistics Canada.

First Call: BC Child and Youth Advocacy Coalition. (2013). 2013 child poverty report card. Vancouver, BC: Author.

First Call: BC Child and Youth Advocacy Coalition. (2014). 2014 child poverty report card. Vancouver, BC: Author.

First Nations Health Council. (2011). Implementing the vision: BC First Nations health governance. Vancouver, BC: Author.

Foley, P. (2007). The socio-economic status of vocational education and training students in Australia. Adelaide, Australia: National Centre for Vocational Education Research Ltd.

Francis, B. (2002). Is the future really female? The impact and implications of gender for 14-16 year olds' career choices. Journal of Education and Work, 15(1), 75-88.

Gale, T., \& Parker, S. (2015). Calculating student aspiration: Bourdieu, spatiality and the politics of recognition. Cambridge Journal of Education, 45(1), 81-96. doi:10.1080/0305764X.2014.988685

Gaventa, J. (2003). Power after Lukes: An overview of theories of power since Lukes and their application to development. Retrieved from http://www.powercube.net/wpcontent/uploads/2009/11/power_after_lukes.pdf

Gonzales, R. G. (2011). Learning to be illegal: Undocumented youth and shifting legal contexts in the transition to adulthood. American Sociological Review, 76(4), 602-619. doi:10.1177/0003122411411901

Grenfell, M., \& James, D. (1998). Bourdieu and education: Acts of practical theory. King's Lynn, UK: Biddles.

Haines, R. J., Poland, B. D., \& Johnson, J. L. (2009). Becoming a 'real'smoker: Cultural capital in young women's accounts of smoking and other substance use. Sociology of Health \& Illness, 31(1), 66-80. 
International Journal of Child, Youth and Family Studies (2016) 7(3/4): 423-455

DOI: http://dx.doi.org/10.18357/ijcyfs73-4201616129

Haines-Saah, R. J., Hilario, C. T., Jenkins, E. J., Ng, C. K. Y., \& Johnson, J .L. (2016). Understanding adolescent narratives about 'bullying' through an intersectional lens: Implications for youth mental health interventions. Youth \& Society, ( Published online before print February 1, 2016). doi:10.1177/0044118X15621465

James, R. (2000). Socioeconomic background and higher education participation: An analysis of school students' aspirations and expectations (Evaluations and Investigations Programme; No. 02/05). Canberra, Australia: Department of Education, Science and Training.

Jenkins, R. (1992). Pierre Bourdieu. London, UK: Routledge.

Jenkins, R. (2002). Pierre Bourdieu: Revised edition. London, UK: Routledge.

Kao, G., \& Thompson, J. S. (2003). Racial and ethnic stratification in educational achievement and attainment. Annual Review of Sociology, 29, 417-442.

Kao, G., \& Tienda, M. (1998). Educational aspirations of minority youth. American Journal of Education, 106, 349-384.

Karnieli-Miller, O., Strier, R., \& Pessach, L. (2009). Power relations in qualitative research. Qualitative health research, 19(2), 279-289. doi:10.1177/1049732308329306

Kessler, Linc. (n.d.). Aboriginal identity and terminology. Retrieved from http://indigenousfoundations.arts.ubc.ca/home/identity/aboriginal-identity-terminology.html

Krahn, H., \& Taylor, A. (2005). Resilient teenagers: Explaining the high educational aspirations of visible-minority youth in Canada. Journal of International Migration and Integration/Revue de l'integration et de la migration internationale, 6(3-4), 405-434.

Lamont, M., Schmalzbauer, J., Waller, M., \& Weber, D. (1996). Cultural and moral boundaries in the U.S.: Structural position, geographic location, and lifestyle explanations. Poetics, 24, 31-56.

Lareau, A. (1989) Home advantage: Social class and parental intervention in elementary education. New York, NY: Falmer Press.

Lareau, A., \& Weininger, E. B. (2003). Cultural capital in educational research: A critical assessment. Theory and society, 32(5-6), 567-606.

Lewis, O. (1963). The culture of poverty. Trans-action, 1(1), 17-19.

Macdonald, D., \& Wilson, D. (2013). Poverty or prosperity: Indigenous children in Canada. Ottawa, ON: Canadian Centre for Policy Alternatives \& Save the Children.

Mandala Center for Change. (n.d.). Theatre of the oppressed. Retrieved from http://www.mandalaforchange.com/applied-theatre/theatre-of-the-oppressed/ 
International Journal of Child, Youth and Family Studies (2016) 7(3/4): 423-455

DOI: http://dx.doi.org/10.18357/ijcyfs73-4201616129

Maurizi, L. K., Ceballo, R., Epstein-Ngo, Q., \& Cortina, K. S. (2013). Does neighborhood belonging matter? Examining school and neighborhood belonging as protective factors for Latino adolescents. American Journal of Orthopsychiatry, 83(2-3), 323-334. doi:10.1111/ajop.12017

Mello, Z. R., \& Swanson, D. P. (2007). Gender differences in African American adolescents' personal, educational, and occupational expectations and perceptions of neighborhood quality. Journal of Black Psychology, 33(2), 150-168. doi:10.1177/0095798407299514

Milestone, K. (2016). ‘Northernness’, gender and Manchester’s creative industries. Journal for Cultural Research, 20(1), 1-15.

Noguera, P.A. (2003). The trouble with black boys: The role and influence of environmental and cultural factors on the academic performance of African American males. Urban Education, 38(4), 431-459. doi:10.1177/0042085903038004005

Noonan, C. (2015) Professional mobilities in the creative industries: The role of "place" for young people aspiring for a creative career, Cultural Trends, 24(4), 299-309, doi:10.1080/09548963.2015.1088121

Norman, M. E., \& Power, N. G. (2015). Stuck between 'the rock'and a hard place: Rural crisis and re-imagining rural Newfoundland feminine subjectivities. Gender, Place \& Culture, 22(1), 50-66.

Osipow, S. H., \& Fitzgerald, L. F. (1996). Theories of career development (4th ed.). Boston, MA: Allyn \& Bacon.

Reay, D. (2004). 'It's all becoming a habitus': Beyond the habitual use of habitus in educational research. British Journal of Sociology of Education, 25(4), 431-444. doi:10.1080/0142569042000236934

Rhoad, M. (2013). Those who take us away: Abusive policing and failures in protection of Indigenous women and girls in northern British Columbia, Canada (Human Rights Watch report). Retrieved from https://www.hrw.org/report/2013/02/13/those-who-take-usaway/abusive-policing-and-failures-protection-indigenous-women

Ristovski-Slijepcevic, S., Bell, K., Chapman, G. E., \& Beagan, B. L. (2010). Being “thick” indicates you are eating, you are healthy and you have an attractive body shape: Perspectives on fatness and food choice amongst Black and White men and women in Canada. Health Sociology Review, 19(3), 317-329. doi:10.5172/hesr.2010.19.3.317

Sewell, W. H. (1971). Inequality of opportunity for higher education. American Sociological Review, 36(5), 793-809. 
International Journal of Child, Youth and Family Studies (2016) 7(3/4): 423-455

DOI: http://dx.doi.org/10.18357/ijcyfs73-4201616129

Spohrer, K. (2011). Deconstructing “aspiration”: UK policy debates and European policy trends. European Educational Research Journal, 10(1), 53-63. doi:10.2304/eerj.2011.10.1.53

Stage, F. K., \& Manning, K. (Eds.). (2015). Research in the college context: Approaches and methods. New York, NY: Routledge.

Statistics Canada. (2011). Table 2: Number and distribution of the population reporting an Aboriginal identity and percentage of Aboriginal people in the population, Canada, provinces and territories, 2011 (National Household Survey, 2011). Ottawa, ON. Retrieved September 20, 2015 from http://www12.statcan.gc.ca/nhs-enm/2011/as-sa/99-011x/2011001/tbl/tbl02-eng.cfm

Statistics Canada. (2012). Focus on geography series, 2011 census (Statistics Canada catalogue no. 98-310-XWE2011004; Analytical products, 2011 census). Ottawa, ON. Retrieved September 1, 2015 from https://www12.statcan.gc.ca/census-recensement/2011/as-sa/fogsspg/Facts-cma-eng.cfm?LANG=Eng\&GK=CMA\&GC=933

Statistics Canada. (2013). [anonymous location], British Columbia: National household survey profile (2011 National Household Survey, Statistics Canada Catalogue no. xx-xxx-xxx. Ottawa, ON. Released September 11, 2013 from [website omitted]

Statistics Canada. (2013). Vancouver, city, British Columbia : National household survey profile (2011 National Household Survey, Statistics Canada catalogue no. 99-004-XWE). Ottawa, ON. Retrieved September 10, 2015 from http://www12.statcan.gc.ca/nhs-enm/2011/dppd/prof/details/page.cfm?Lang=E\&Geo1=CSD\&Code1=5915022\&Data=Count\&SearchTe $\underline{\mathrm{xt}=\text { Vancouver\&SearchType }=\text { Begins\&SearchPR }=01 \& \mathrm{~A} 1=\mathrm{All} \& \mathrm{~B} 1=\mathrm{All} \& \text { Custom }=\text { \&TABID }}$ $=1$

Statistics Canada. (2015). Classification of visible minority. Retrieved October 1, 2015 from www.statcan.gc.ca/eng/concepts/definitions/minority01a

Stempel, C. (2005). Adult participation in sports as cultural capital - A test of Bourdieu's theory of the field of sports, International Review for the Sociology of Sport, 40(4), 411-432.

Stewart, E. B., Stewart, E. A., \& Simons, R. L. (2007). The effect of neighborhood context on the college aspirations of African American adolescents. American Educational Research Journal, 44(4), 896-919. doi:10.3102/0002831207308637

Terdiman, R. (1987). Translator's introduction. In P. Bourdieu, The force of law: Toward a sociology of the juridical field. The Hastings Law Journal, 38(1971), 805-853.

Thiessen, V. (2009). The pursuit of postsecondary education: A comparison of First Nations, African, Asian, and European Canadian youth. Canadian Review of Sociology/Revue canadienne de sociologie, 46(1), 5-37. 
International Journal of Child, Youth and Family Studies (2016) 7(3/4): 423-455

DOI: http://dx.doi.org/10.18357/ijcyfs73-4201616129

Thornton, S. (1996). Club cultures: Music, media and subcultural capital. Hanover and London, UK: Wesleyan University Press.

Veenstra, G., \& Burnett, P. J. (2014). A relational approach to health practices: Towards transcending the agency-structure divide. Sociology of Health and Illness, 36(2), 187-198. $\underline{\text { doi:10.1111/1467-9566.12105 }}$

Walpole, M. (2003). Socioeconomic status and college: How SES affects college experiences and outcomes. The Review of Higher Education, 27(1), 45-73. doi:10.1353/rhe.2003.0044

Watson, C. M., Quatman, T., \& Edler, E. (2002). Career aspirations of adolescent girls: Effects of achievement level, grade, and single-sex school environment. Sex Roles, 46, 323-335.

Wiles, J. L., Rosenberg, M. W., \& Kearns, R. A. (2005). Narrative analysis as a strategy for understanding interview talk in geographic research. Area, 37(1), 89-99. doi:10.1111/j.1475-4762.2005.00608.x

Williams, S. J. (1995). Theorising class, health and lifestyles: Can Bourdieu help us? Sociology of Health and IIlness, 17(5), 577-604.

Wilson, W. J. (2010). Why both social structure and culture matter in a holistic analysis of innercity poverty. The ANNALS of the American Academy of Political and Social Science, 629(1), 200-219. doi:10.1177/0002716209357403

Yoshikawa, H., Aber, J. L., \& Beardslee, W. R. (2012). The effects of poverty on the mental, emotional, and behavioral health of children and youth: Implications for prevention. American Psychologist, 67(4), 272-284. doi:10.1037/a0028015 